\title{
A RARE CAUSE OF ACUTE FLACCID PARALYSIS
}

\author{
Santhosh Kumar P1, Lakshmi Marappan², Preetam Arthur ${ }^{3}$
}

1 Junior Resident, Department of General Medicine, Sri Ramachandra Medical College and Hospital, (SRMC), Porur, Chennai. ${ }_{2}^{2}$ Assistant Professor, Department of General Medicine, Sri Ramachandra Medical College and Hospital, (SRMC), Porur, Chennai. 3 Professor and HOD, Department of General Medicine, Sri Ramachandra Medical College and Hospital, (SRMC), Porur, Chennai.

HOW TO CITE THIS ARTICLE: Kumar SP, Marappan L, Arthur P. A rare cause of acute flaccid paralysis. J. Evolution Med. Dent. Sci. 2017;6(88):6165-6166, DOI: 10.14260/jemds/2017/1339

\begin{tabular}{|c|c|}
\hline $\begin{array}{l}\text { PRESENTATION OF CASE } \\
\text { Tick paralysis is a preventable cause of illness and death that } \\
\text { when diagnosed promptly requires simple low-cost } \\
\text { intervention (Tick removal). In India, the discovery of the } \\
\text { tick-borne viral disease, i.e. Kyasanur Forest Disease (KFD) in } \\
1957 \text { marked a milestone in the history of tick studies. The } \\
\text { typical presentation is a prodrome followed by the } \\
\text { development of an unsteady gait and then ascending } \\
\text { symmetrical flaccid paralysis. Early cranial involvement is a } \\
\text { feature, particularly the presence of both internal and } \\
\text { external ophthalmoplegia. Neurophysiological studies reveal }\end{array}$ & $\begin{array}{l}\text { ECG, chest x-ray and ultrasound abdomen were all } \\
\text { normal. CSF analysis showed no cells, proteins were } 44 \\
\text { mg/dL and sugars were } 52 \mathrm{mg} / \mathrm{dL} \text {. There was no oligoclonal } \\
\text { bands and cultures also showed no growth. } \\
\text { Neuroimaging showed normal studies in CT brain, MRI } \\
\text { brain and also in cervical spine. Neurologist's opinion was } \\
\text { sought and nerve conduction study was done which showed } \\
\text { severe motor radiculoneuropathy. Sensory study and } \\
\text { repetitive nerve stimulation study were normal. In suspicion } \\
\text { of Guillain-Barre syndrome, patient was planned for } \\
\text { IVIG/plasmapheresis. }\end{array}$ \\
\hline
\end{tabular}
low-amplitude compound muscle action potentials with normal motor conduction velocities, normal sensory studies and normal response to repetitive stimulation. We report a 21 years old male presenting with acute flaccid paralysis.

A 21 years old male with no previous comorbidities was referred to our institution as a case of acute flaccid paralysis for further evaluation. He came with 24 hours history of vomiting, fatigability later becoming unsteady and requiring assistance to walk to a nearby hospital. No history of alcohol intake and drug use. He was admitted in the outside hospital and over the next 24 hours he developed progressive weakness, first of the lower limbs and then the upper limbs. He also developed respiratory paralysis and had to be intubated. In suspicion of a snake bite, he was given 10 vials of ASV (Anti-snake venom) and also given a shot of pyridostigmine. He was then admitted in our institution for further diagnostic evaluation.

At the time of admission, he was conscious, tried to open his eyes to calls with mild wrinkling of eyebrows but complete ptosis present. Bilateral pupils were $3 \mathrm{~mm}$ and not reacting. He had complete ophthalmoplegia, both internal and external. Also had bilateral facial weakness near total except for mild wrinkling of eyebrows. Flaccid paralysis of all four limbs and power of $0 / 5$ in all limbs. Deep tendon reflexes were also absent.

\section{DIFFERENTIAL DIAGNOSIS}

After considering initial clinical presentation of the patient's possibilities of neurotoxic snake envenomation, botulism, injury to head and spine, Guillain-Barre Syndrome, unknown toxin and myasthenic crisis were all looked into. The full blood count and all biochemical profiles were normal.

'Financial or Other Competing Interest': None.

Submission 15-10-2017, Peer Review 28-10-2017,

Acceptance 30-10-2017, Published 06-11-2017.

Corresponding Author:

Dr. Santhosh Kumar P,

Tower 3B Prestige Bella Vista,

Kattupakkam, Door. No. 3186,

Chennai -56.

E-mail: drsanthosh1991@gmail.com

DOI: $10.14260 /$ jemds/2017/1339

\section{CLINICAL DIAGNOSIS}

Meanwhile, patient's motor function started improving on day 2 and complete recovery of motor function was achieved on day 3 of admission, except for internal ophthalmoplegia which improved on day 5. Patient was also extubated on day 3 , hence plasmapheresis was deferred and GBS was ruled out of the diagnosis. Upon recovery and recall of events, the patient gave a history of insect bite over the right axilla, although there was no evidence of bite mark upon examination on arrival. Repeat NCS was done which turned out to be normal and with the history of insect bite clinical and electrophysiological findings fitting in diagnosis of tick paralysis was made. Patient recovered uneventfully and discharged.

\section{PATHOLOGICAL DISCUSSION}

Tick paralysis is caused by tick bite and typically presents as a flaccid ascending paralysis.(1) Tick paralysis was first described by explorers in the Australian outback in 1824.(2) Ticks are currently considered to be second only to mosquitoes as vectors of human infectious diseases in the world. Each tick species has preferred environmental conditions and biotypes that determine the geographic distribution of the ticks and consequently the risk areas for tick-borne diseases.(3)

Ticks transmit a number of infections to humans and other animals. However, the toxins of various ticks can also cause a disease known as tick paralysis, which can be confused with both infectious and non-infectious conditions. Although, it is a rare disease in humans, tick paralysis is important to recognize because it can be fatal or nearly fatal.(4) However, if diagnosed promptly, this illness can be cured with the combination of tick removal and supportive care.

There are more than 800 known species of argasid (soft shelled) and ixodes (hard-shelled) ticks and over 40 individual tick species are capable of causing salivary toxins that can cause paralysis in humans and animals.(5) Studies in India have shown that there are 109 species in India, out of which 88 belong to the family Ixodidae of hard ticks. ${ }^{(6,7,8)}$ All case reports in India are mainly on livestocks and wild animals. 
It is an ascending flaccid paralysis caused by the bite of tick. The clinical features include weakness, myalgia followed by unsteady gait. Then the patient develops paralysis in ascending pattern. Sensory system is usually intact and there will be no fever in tick paralysis. Internal and external ophthalmoplegia is characteristic of tick paralysis. Respiratory paralysis develops finally. All the features develop within 3 - 5 days of bite of a tick.

The biological effect of tick salivary toxins is in part specific to the species of tick. The toxin produced by the tick interrupts the sodium flux across axonal membranes in selected locations such as the nodes of Ranvier and nerve terminals.(9) All biochemical parameters are essentially normal and CSF analysis also shows normal study. Imaging studies are also characteristically normal.(10) Electrophysiological studies are vital in arriving at the diagnosis. Motor conduction velocity slows and returns to more normal values in parallel with clinical improvement. Repetitive stimulation of the motor nerve reveals no fatigue and the amplitude of muscle-action potential. Sensory nerve conduction study is characteristically normal.(11)

\section{DISCUSSION OF MANAGEMENT}

The rapid onset and recovery of the neurological symptoms coupled with presence of internal and external ophthalmoplegia and characteristic nerve conduction studies helps us to differentiate tick paralysis from other conditions causing neuromuscular paralysis. With removal of the tick, the signs and symptoms subside rapidly and recovery is complete within a few days. The paralysis disappears in a descending order. It has been said that the greatest amount of toxin is produced on the fifth and sixth days after the tick has attached itself to the host. Some sensory changes may be present. When bulbar paralysis appears, the lower cranial nerves are paralyzed first and this is followed by involvement of the face and extraocular muscles and finally the respiratory muscles.

\section{FINAL DIAGNOSIS}

How final diagnosis was arrived at is already mentioned in clinical diagnosis.

\section{REFERENCES}

[1] Edlow JA, McGillicuddy DC. Tick paralysis. Infect Dis Clin North Am 2008;22(3):397-413.

[2] Scott E. Hume and Howell's journey to Port Phillip. R Aust Histo Soc J and Proc 1921;7:289.

[3] Parola P, Raoult D. CNRS UMR 6020. 2000.

[4] Schaumburg HH, Herskovitz S. The weak child--a cautionary tale. N Engl J Med 2000;342(2):127-9.

[5] Gothe R, Kunze K, Hoogstraal H. The mechanisms of pathogenicity in the tick paralyses. J Med Entomol 1979;16(5):357-69.

[6] Geevarghese G, Fernandes S, Kulkarni SM. A checklist of Indian ticks. The Indian Journal of Animal Sciences 1997;67(5):566-74

[7] Ghosh S, Azhahianambi P, Yadav MP. Upcoming and future strategies of tick control: a review. Journal of Vector Borne Diseases 2007;44(2):79-89.

[8] Ghosh S, Bansal GC, Gupta SC, et al. Status of tick distribution in Bangladesh, India and Pakistan. Parasitology Research 2007;101(Suppl 2):s207-s16.

[9] Felz MW, Smith CD, Swift TR. A six-year-old girl with tick pralysis. N Engl J Med 2000;342(2):90-4.

[10] Burke MS, Fordham LA, Hamrick HJ. Ticks and tick paralysis: imaging findings on cranial MR. Pediatr Radiol 2005;35(2):206-8.

[11] Vedanarayanan VV, Evans OB, Subramony SH. Tick paralysis in children: electrophysiology and possibility of misdiagnosis. Neurology 2002;59(7):1088-90. 